\title{
Reasons for medical evacuations of soldiers serving in International Security Assistance Force (ISAF) operation in Afghanistan
}

\author{
Krzysztof Korzeniewski ${ }^{1}$, Robert Gregulski ${ }^{2}$
}

${ }^{1}$ Department of Epidemiology and Tropical Medicine in Gdynia, Military Institute of Medicine, Warsaw, Poland

${ }^{2}$ Operations Command of the Polish Armed Forces in Warsaw, Poland

\begin{abstract}
Background: The article presents the results of a research study into the reasons for medical evacuations of Polish military personnel taking part in the International Security Assistance Force (ISAF) operation in Afghanistan from 2007 to 2013.

Materials and methods: The authors have analysed medical records of 485 soldiers who were medically evacuated out of a combat zone in Afghanistan for battle injuries, non-battle injuries and diseases. Each medically evacuated Polish soldier was subjected to statistical analysis. The study population comprised 25,974 soldiers assigned to the Polish Military Contingent Afghanistan in the given period.

Results: From 2007 to 2013, 1.9\% of the Polish military personnel $(n=485)$ participating in the ISAF operation in Afghanistan were evacuated for medical reasons before the scheduled termination of their contract. $40.6 \%$ of all medical evacuations were due to battle injuries, $32.4 \%$ due to non-battle injuries, and $27.0 \%$ due to diseases.

Conclusions: ISAF is an example of a combat operation, in which battle injuries remain the leading health problem in mission participants. 3 of 4 Polish soldiers who were medically evacuated from Afghanistan were no longer fit for military service in the area of operations due to the traumas they had suffered.
\end{abstract}

(Int Marit Health 2014; 65, 4: 210-215)

Key words: medical evacuations, Afghanistan, soldiers

\section{INTRODUCTION}

\section{ORGANISATION OF MEDICAL EVACUATION IN THE POLISH MILITARY CONTINGENT (PMC) IN AFGHANISTAN}

Medical evacuation is a process of transferring the sick or wounded personnel to an appropriate medical treatment facility. All causalities should receive first-aid at the scene of incident as soon as possible (life-saving procedures, e.g. cardiopulmonary resuscitation or stabilisation of vital functions ought to be performed within 60 min following the incident - the so called 'golden hour'). In exceptional circumstances, under operational conditions, the 'golden hour' may be extended to 120 min on condition that a casualty is evacuated directly to a Role 2 or 3 medical facility. Surgical procedures should be performed within a maximum of $4 \mathrm{~h}$ following an incident. There are four categories of medical evacuation precedence:

- Urgent Medevac - medical evacuation within a maximum of $2 \mathrm{~h}$, it is carried out in order to save life/limb/ /vision, prevent serious complications or to avoid permanent disability (burns exceeding $20 \%$ of the body surface

Krzysztof Korzeniewski, MD, PhD, Professor at Military Institute of Medicine, Department of Epidemiology and Tropical Medicine, ul. Grudzińskiego 4, 81-103 Gdynia,

Poland, e-mail: kktropmed@wp.pl 
area, non-treatable shock, prolonged loss of consciousness, respiratory and circulatory failure, open chest wounds, excessive bleeding, critical limb ischaemia);

- Priority Medevac - medical evacuation of the sick and wounded requiring prompt medical care within a maximum of $4 \mathrm{~h}$ to prevent further deterioration of their condition (closed chest wounds, burns of extremities, fractures);

- Routine Medevac - medical evacuation of patients whose condition is not expected to deteriorate, it is carried out within $24 \mathrm{~h}$ (psychiatric patients, open wounds without respiratory complications);

- Convenience Medevac - it is assigned to patients for whom medical evacuation is a matter of medical convenience rather than necessity; it is carried out within $72 \mathrm{~h}[1,2]$.

Strategic medical evacuation (Stratevac), i.e. transferring a patient from a mission area back to home country is launched if a soldier cannot be returned to duty within 21 days or if he/she requires highly-specialised treatment which is unavailable in the area of operations. Stratevac can take the following forms:

- diagnostic - due to limited diagnostic capabilities in the theatre, delayed diagnosis may result in irreversible or serious health damage;

- therapeutic - due to limited therapeutic capabilities in the theatre;

- health-related - if a patient is no longer fit for military service in the area of operations due to injuries or diseases.

Stratevac from Afghanistan can take the form of a single- or a two-stage evacuation:

- single-stage evacuation - transfer of a casualty from the area of operations to a Role 4 medical treatment facility in Poland (conducted by the Polish Air Force);

- two-stage evacuation - transfer of a casualty from the area of operations to the United States military base in Ramstein, Germany (a Role 4 Landstuhl Regional Medical Centre) and next to a medical treatment facility in Poland.

The sick or wounded PMC personnel who were first transferred to Germany are then transported to Poland either by air or overland, depending on their condition. Casualties in serious condition are taken to Poland on board of a CASA $295 \mathrm{M} / \mathrm{AN}-26$ flying from the $8^{\text {th }}$ Transportation Base in Krakow and are assisted by a medical team consisting of a medical doctor, a nurse anaesthetist and a paramedic. The CASA aircraft is equipped with all necessary medical equipment for saving, monitoring and supporting vital functions of a transported patient. Polish patients are transferred to one of the 4 Polish military clinical hospitals (in Warsaw, Wroclaw, Krakow or Bydgoszcz) [3].
The aim of the article was to present the results of a research study into the reasons for medical evacuations of Polish military personnel who were deployed to International Security Assistance Force (ISAF) operation in Afghanistan between 2007 and 2013.

\section{MATERIALS AND METHODS}

\section{STUDY POPULATION}

The authors have analysed medical records of 485 soldiers who were medically evacuated from a combat zone in Afghanistan due to battle injuries, non-battle injuries and diseases during the period from 2007 to 2013. Each of the medically evacuated Polish soldiers was subjected to statistical analysis. The study population comprised 25,974 soldiers assigned to PMC Afghanistan in the given period.

\section{STATISTICS}

The diagnosed diseases and injuries were analysed in line with the ICD-10 classification: contagious and parasitic diseases, psychiatric disorders, neurological, eye, cardiovascular, respiratory, gastrointestinal, skin, musculoskeletal, urogenital diseases, and injuries (battle and non-battle). The basis for calculating the intensity rate of medical evacuations was the number of evacuated patients according to diagnosed diseases or injuries used as a numerator and the total number of the study population in a given period used as a denominator $(n=25,974)$, multiplied by the coefficient $C=10^{k}(k=0,1,2,3 \ldots$, in this statistical analysis $k=3$ ).

The statistical analysis was performed using the statistical suite StatSoft Inc. (2011) STATISTICA (data analysis software system), version 10.0. (SN JGNP3087539302AR-E) and Excel.

\section{RESULTS}

485 Polish soldiers participating in the ISAF operation between 2007 and 2013 were evacuated from Afghanistan for medical reasons, which accounted for $1.9 \%$ of the total Polish troop strength $(n=25,974)$ relocated to the area of operations during the given period. $40.6 \%$ of all medical evacuations were due to battle injuries, $32.4 \%$ due to non-battle injuries, and $27.0 \%$ due to diseases (Fig. 1).

The intensity of medical evacuations in the population of Polish soldiers deployed to Afghanistan increased in the period from 2010 to 2011, when as many as 251 servicemen were evacuated before the scheduled termination of their 6 -month contract (52\% of all evacuations in the period 2007-2013) (Fig. 2).

The majority of medically evacuated soldiers were in the rank of private $(47.8 \%)$ and non-commissioned officer (36.5\%) aged 26-35 (72.9\%). 


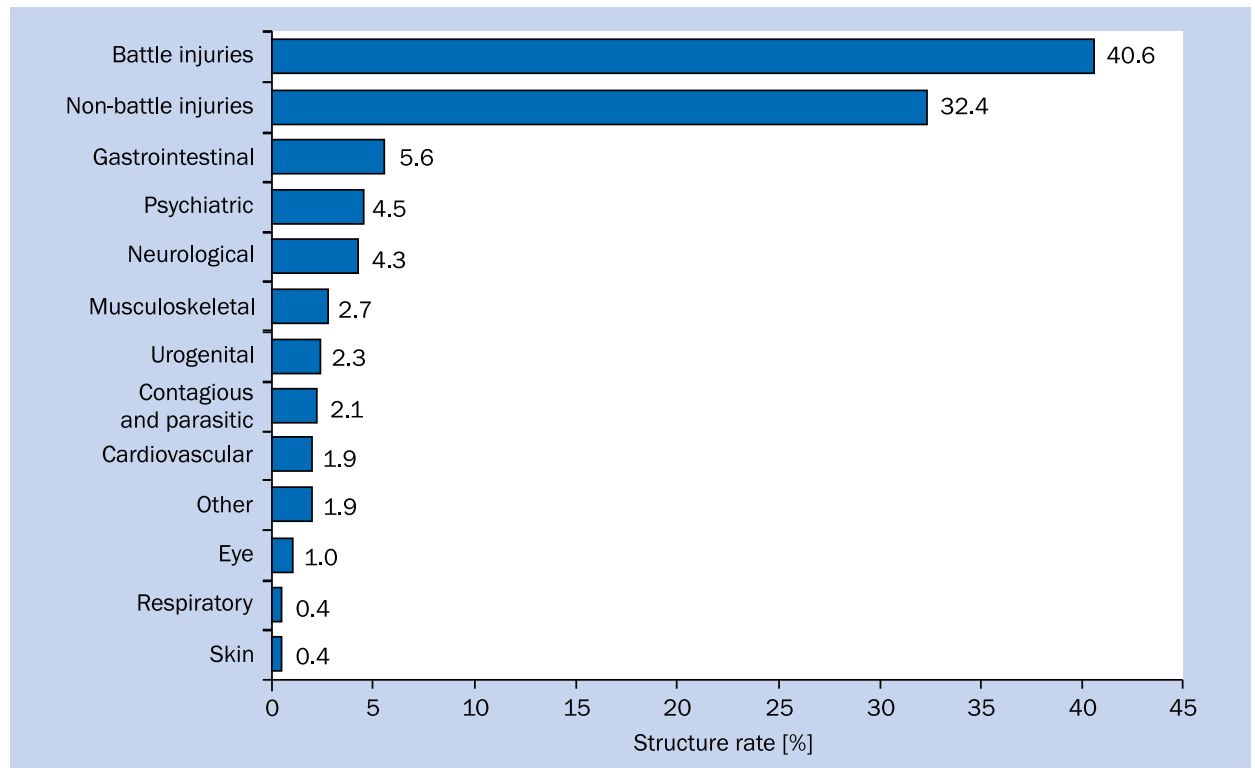

Figure 1. Medical evacuations of soldiers serving in Polish Military Contingent deployed to Afghanistan between 2007 and 2013 ( $n=485$ )

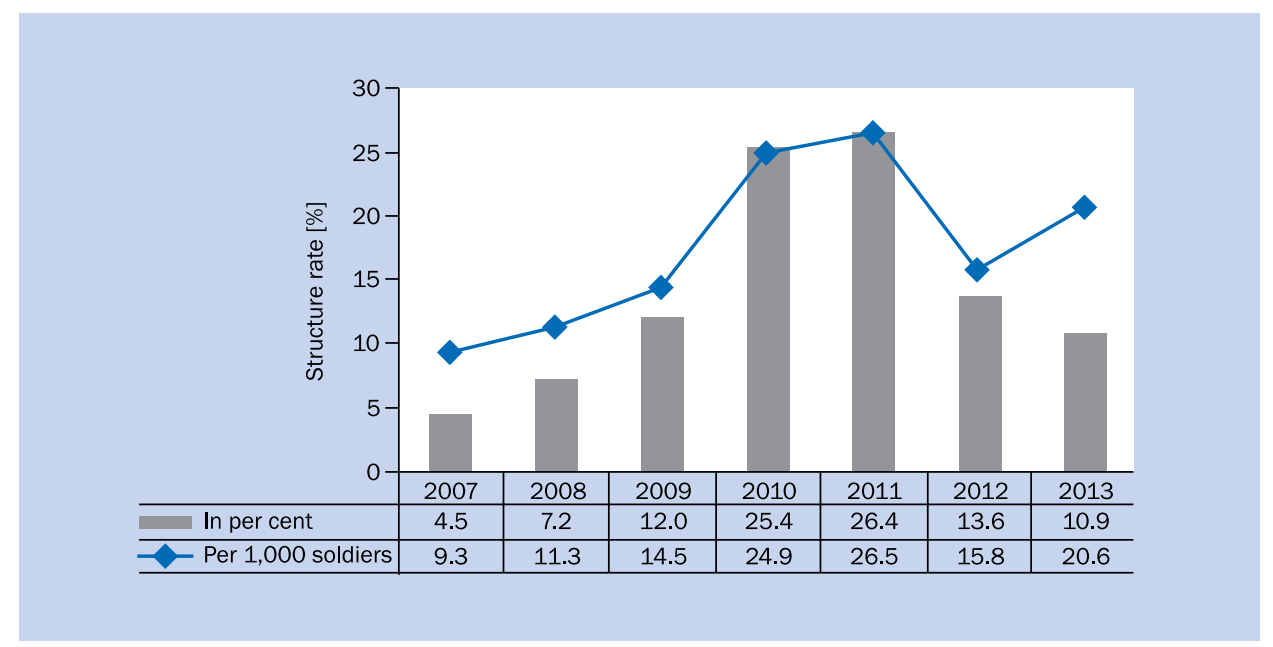

Figure 2. Medical evacuations of soldiers serving in Polish Military Contingent deployed to Afghanistan between 2007 and 2013 ( $n=485$ )

\section{MEDICAL EVACUATIONS DUE TO BATTLE INJURIES}

Of all service members of the PMC deployed to Afghanistan between 2007 and 2013, 197 were medically evacuated due to battle injuries ( $40.6 \%$ of all medical evacuations during the surveillance period). The majority of battle injuries suffered by PMC personnel were caused by improvised explosive devices (IEDs), mortar shells, Rocket Propelled Grenade Launcher shells and small arms. Battle injured soldiers were mainly evacuated for bone fractures (20.8\%), shrapnel wounds (19.8\%), gunshot wounds (16.8\%) and multiple organ injuries (15.7\%) (Table 1).

Battle injuries such as fractures or shrapnel wounds were mainly located on lower limbs, whereas gunshot wounds on upper limbs (Table 2). 95\% of all irrecoverable personnel losses (41 soldiers) suffered during the analysed period were due to combat-related injuries.

The deaths of PMC personnel most commonly resulted from multiple-organ injuries (85\%) and craniocerebral traumas (15\%). The highest intensity rate of medical evacuations for battle injuries was reported between 2010 and 2011 (Fig. 3), which was associated with the intensification of the military kinetic actions in the theatre of operations during the given period.

\section{MEDICAL EVACUATIONS DUE TO NON-BATTLE INJURIES}

157 PMC Afghanistan soldiers were medically evacuated out of the Afghan theatre due to non-battle injuries, 
which accounted for $32.4 \%$ of all medical evacuations in the period 2007-2013. Non-battle injuries commonly resulted from non-compliance with health and safety rules while carrying out professional duties as well as from the lack of skill or carelessness while practicing sport (gym, cross-country running). Non-battle injured Polish servicemen

Table 1. Battle injuries in Polish Military Contingent soldiers medically evacuated from Afghanistan during the period $2007-2013$

\begin{tabular}{lll}
\hline Battle injuries & $\mathbf{n}$ & $\begin{array}{l}\text { Intensity rate per } \\
\mathbf{1 , 0 0 0} \text { soldiers } \\
\mathbf{( n = 2 5 , 9 7 4 )}\end{array}$ \\
\hline Bone fractures & 41 & 1.6 \\
Shrapnel wounds & 39 & 1.5 \\
Gunshot wounds & 33 & 1.3 \\
Multiple organ injuries & 31 & 1.2 \\
Musculoskeletal contusion & 24 & 0.9 \\
Craniocerebral trauma & 22 & 0.8 \\
Post-traumatic limb amputation & 4 & 0.2 \\
Acoustic trauma & 3 & 0.1 \\
Total & 197 & 7.6
\end{tabular}

were mainly evacuated for bone fractures $(40.8 \%)$ or joint sprains (30.6\%) (Table 3).

The highest intensity rate of medical evacuations for non-battle injuries, similarly to battle injuries, was reported between 2010 and 2011 (Fig. 4).

Table 3. Non-battle injuries in Polish Military Contingent soldiers medically evacuated from Afghanistan during the period $2007-2013$

\begin{tabular}{|c|c|c|}
\hline Non-battle injuries & $\mathbf{n}$ & $\begin{array}{l}\text { Intensity rate per } \\
1,000 \text { soldiers } \\
(n=25,974)\end{array}$ \\
\hline Bone fracture & 64 & 2.5 \\
\hline Joint sprain & 48 & 1.8 \\
\hline Tendon injury & 15 & 0.6 \\
\hline Musculoskeletal contusion & 12 & 0.5 \\
\hline Self-inflicted gunshot wound & 8 & 0.3 \\
\hline Craniocerebral trauma & 3 & 0.1 \\
\hline Superficial contusion or laceration & 3 & 0.1 \\
\hline $1^{\text {st }}$ or $2^{\text {nd }}$ degree skin burn & 2 & 0.1 \\
\hline Eye injury & 2 & 0.1 \\
\hline Total & 157 & 6.1 \\
\hline
\end{tabular}

Table 2. Location of fractures, gunshot and shrapnel wounds in Polish Military Contingent soldiers medically evacuated from Afghanistan during the period $2007-2013$

\begin{tabular}{llllll}
\hline Battle injuries & Upper limb & Lower limb & Trunk, pelvis, spine & Head, neck & Total \\
\hline Fractures & 11 & 21 & 6 & 3 & 41 \\
Shrapnel wounds & 10 & 17 & 8 & 4 & 39 \\
Gunshot wounds & 14 & 11 & 6 & 2 & 33 \\
Total & 25 & 49 & 20 & 9 & 113
\end{tabular}

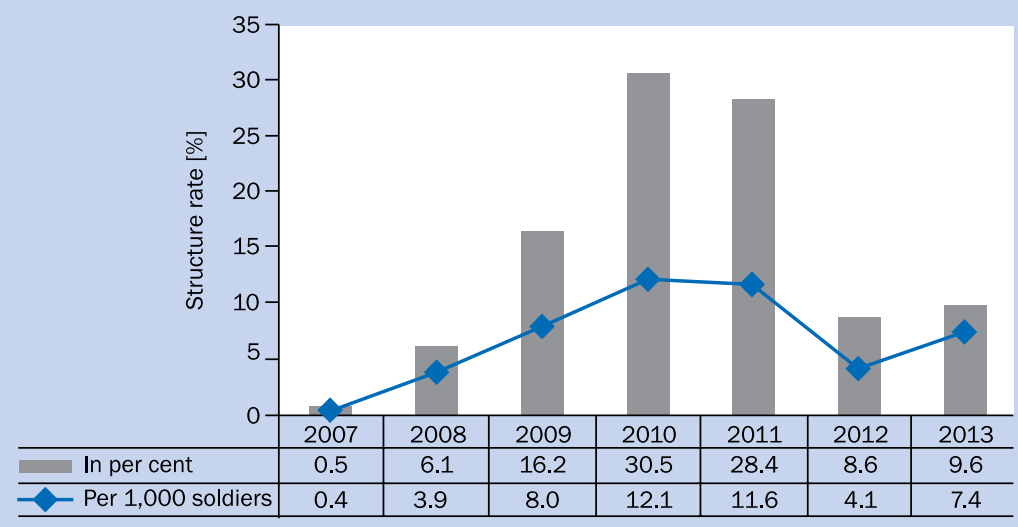

Figure 3. Rates of medical evacuations due to battle injuries among Polish Military Contingent Afghanistan personnel during the period 2007-2013 ( $=197)$ 


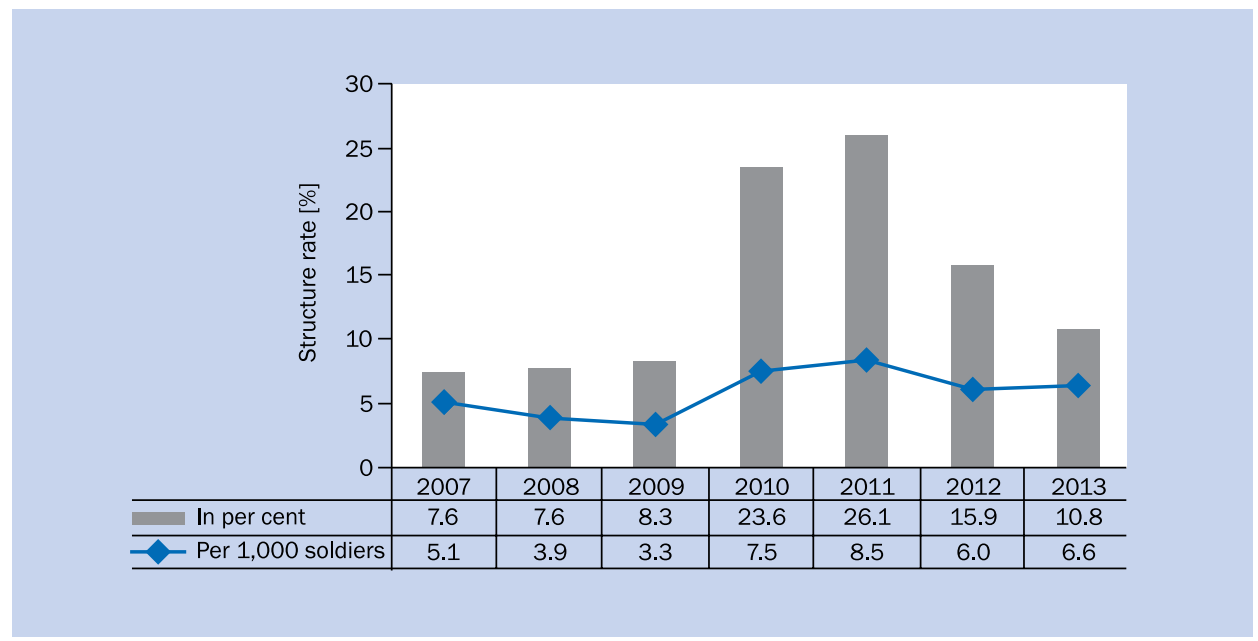

Figure 4. Medical evacuation due to non-battle injuries among Polish Military Contingent Afghanistan personnel during the period 2007-2013 $(n=157)$

\section{MEDICAL EVACUATIONS DUE TO DISEASES}

131 Polish servicemen were medically evacuated due to diseases (27.0\% of all evacuations in the period 2007-2013). Military personnel were mainly evacuated for back pain, hernia, adaptation disorder (Table 4).

The highest intensity rate of medical evacuations for diseases was reported in 2011 (Fig. 5).

\section{DISCUSSION}

More than 2.5 million coalition soldiers have served in operations ‘Enduring Freedom' and 'Iraqi Freedom'. Tens of thousands of the military personnel were battle-injured and $46 \%$ of the wounded soldiers had to be medically evacuated out of the theatre of operations to their home countries. The traumatic profile was dominated by shrapnel wounds and multiple organ injuries suffered in the explosion of IEDs, anti-personnel mines, mortar rounds and grenades $[4,5]$. The United States Forces health service whose task, among others, is to conduct epidemiological surveillance in the United States Armed Forces consisting of 1.5 million active duty members, holds comprehensive data on health status of the United States soldiers as well as on the exact number of medical evacuations from areas of operations around the world. According to the data, of 1.7 million United States servicemen deployed to Afghanistan between 2001 and 2012; 23,000 (38.5 per 1,000 soldiers/year) were medically evacuated to their home country. The most common reasons for medical evacuation of the United States servicemen in the surveillance period were battle injuries (5,647 casualties; 23.8\%; 9.2 per 1,000 soldiers/ /year) followed by musculoskeletal diseases (3,427 patients; 14.4\%; 5.6/1,000 soldiers/year), non-battle injuries (3,398 casualties; 14.3\%), psychiatric disorders (2,850; 12.0\%), gastrointestinal diseases $(1,142 ; 4.8 \%)$, neurological dis-
Table 4. Diseases in Polish Military Contingent soldiers medically evacuated from Afghanistan in the period 2007-2013

\begin{tabular}{lll}
\hline Diseases & n & $\begin{array}{l}\text { Intensity rate per } \\
\mathbf{1 , 0 0 0} \text { soldiers (n = 25,974) }\end{array}$ \\
\hline Back pain & 10 & 0.4 \\
Hernia & 10 & 0.4 \\
Adaptation disorders & 8 & 0.3 \\
Urolithiasis & 6 & 0.2 \\
Loss of consciousness & 6 & 0.2 \\
Acute stress disorder & 5 & 0.2 \\
Posttraumatic stress disorder & 4 & 0.2 \\
Peptic ulcer & 4 & 0.2 \\
Q fever & 4 & 0.2 \\
Thrombophlebitis & 3 & 0.1 \\
Epilepsy & 3 & 0.1 \\
Migraine headaches & 3 & 0.1 \\
Ileus & 3 & 0.1 \\
Malaria & 2 & 0.1 \\
Hypertension & 2 & 0.1 \\
Dental diseases & 2 & 0.1 \\
Cholecystitis & 2 & 0.1 \\
Appendicitis & 2 & 0.1 \\
Other & 52 & 2.0 \\
Total & 131 & 5.1 \\
& & \\
& &
\end{tabular}

eases (1,105; 4.7\%), urogenital diseases (1,028; 4.3\%), cardiovascular diseases (735; 3.1\%), skin diseases (309; $1.3 \%)$, contagious and parasitic diseases (232; $1.0 \%)$, pregnancy and childbirth (103 cases). A total of $38.1 \%$ of the United States Forces soldiers were medically evacuated 


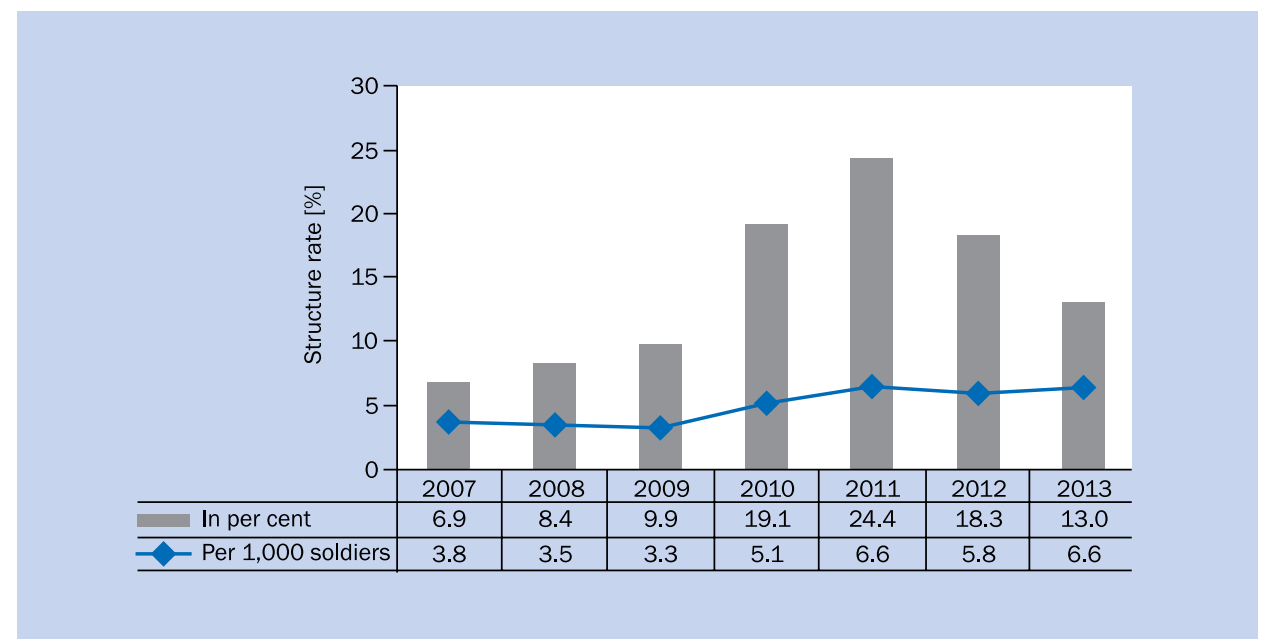

Figure 5. Medical evacuation due to diseases among Polish Military Contingent Afghanistan personnel during the period 2007-2013 ( $n=131)$

due to battle or non-battle injuries, $61.9 \%$ owing to diseases. As regards diseases, the leading causes of evacuation out of a war zone included adaptation disorders, joint and spine injuries/diseases. $40.1 \%$ of the medically evacuated soldiers were treated on an in-patient, while $59.5 \%$ on an out-patient basis [6]. In comparison with the United States Forces personnel medically evacuated from wartime theatres around the world, Polish soldiers deployed to Afghanistan were significantly more often evacuated for battle injuries (40.6\% vs. 23.8\%) and for non-battle injuries (32.4\% vs. $14.3 \%)$, while significantly less often evacuated for diseases (27.0\% vs. $61.9 \%$ ).

Authors of this paper have observed an even greater disproportion in the morbidity and traumatic profiles between Polish and Spanish military personnel. The research study conducted by Suay et al. [7] focusing on 232 Spanish soldiers who were medically evacuated from operational areas (mostly from Afghanistan: 47\% and Lebanon: 19\%) to Spain (Central Hospital of Defence in Madrid, Role 4) between 2008 and 2013 indicated that $91 \%$ of the soldiers required medical evacuation out of the theatre due to diseases and non-battle injuries (diseases: $54 \%$, traffic accident injuries: $23 \%$, sports injuries: $14 \%$ ). Battle injuries were the cause of only $9 \%$ of all medical evacuations ( $5 \%$ were due to shell fragment wounds suffered in IED explosions, $4 \%$ were due to gunshot wounds). Other than combat-related causes of medical evacuations included psychiatric disorders, such as adaptation disorders, anxiety, and depression (12\%), cardiovascular diseases (9\%), gynaecological diseases/ /conditions (7\%), neurological (6\%), gastrointestinal (6\%), urogenital diseases (5\%) [7].

The above-mentioned data clearly demonstrates that the military operation carried out in Afghanistan is a combat mission. A substantial number of irrecoverable personnel losses and medical evacuations out of the Afghan theatre were due to traumas sustained in combat. The findings suggest that it is necessary to adapt the tasks and practices of the medical support services so that they would meet the requirements of contemporary military operations.

\section{CONCLUSIONS}

ISAF is an example of a combat operation, in which battle injuries remain the leading health problem in mission participants. 3 out of 4 Polish soldiers who were medically evacuated from Afghanistan were no longer fit for military service in operational conditions due to traumas they had suffered.

\section{REFERENCES}

1. Korzeniewski K, Juszczak D, Gregulski R. Medical support and health problems in soldiers of the PMC Afghanistan in a case study of Giro and Qarabagh military bases. [in Polish]. Lek Wojsk 2012; 90: 349-353.

2. Korzeniewski K, Bochniak A. Medical support of military operations in Iraq and Afghanistan. Int Marit Health 2011; 62: 71-76.

3. Korzeniewski K, Pieniuta S, Nowak B et al. Zadania i struktura organizacyjna służby zdrowia Polskiego Kontyngentu Wojskowego w Afganistanie. [in Polish]. Lek Wojsk 2011; 89: 364-375.

4. Clark ME, Bair MJ, Buckenmaier CC et al. Pain and combat injuries in soldiers returning from Operations Enduring Freedom and Iraqi Freedom: Implications for research and practice. J Rehabil Res Develop 2007; 44: 179-194.

5. Marshall TJ. Combat casualty care: the Alpha Surgical Company experience during Operation Iraqi Freedom. Mil Med 2005; 170 : 469-472.

6. Medical Surveillance Monthly Report. Medical Evacuations from Afghanistan during Operation Enduring Freedom, Active and Reserve Components, U.S. Armed Force, 7 October 2001 - 31 December 2012. MSMR 2013; 20: 2-8.

7. Suay RN, Bariain RT, Ortega CG et al. Analysis of Evacuations From Areas of Operation to the Spanish Role 4 Medical Treatment Facility (2008-2013). Mil Med 2014; 179: 71-75. 